\title{
Phylogenetic analysis of the genus Actinoplanes and transfer of Actinoplanes minutisporangius Ruan et al. 1986 and 'Actinoplanes aurantiacus' to Cryptosporangium minutisporangium comb. nov. and Cryptosporangium aurantiacum sp. nov.
}

Institute for Fermentation, Osaka, 17-85 Juso-honmachi 2-chome, Yodogawa-ku, Osaka 532-8686, Japan

\section{Tomohiko Tamura and Kazunori Hatano}

\author{
Author for correspondence: Tomohiko Tamura. Tel: +816300 6555. Fax: +81 63006814 . \\ e-mail: tamura-tomohiko@ifo.or.jp
}

\begin{abstract}
The phylogenetic structure of the genus Actinoplanes was determined by comparative $16 \mathrm{~S}$ rDNA sequence analysis of the type strains of all validly described Actinoplanes species and other strains of Actinoplanes. Actinoplanes minutisporangius IFO 15962' $^{\top}$ and 'Actinoplanes aurantiacus' IFO 13967 were placed outside the family Micromonosporaceae and appeared to be closely related to the genus Cryptosporangium. On the basis of their morphological and chemotaxonomic characteristics and phylogenetic analysis, these strains were reclassified into the genus Cryptosporangium. DNA-DNA hybridization revealed that these strains differed from the species previously described in this genus. Therefore, the transfer is proposed of Actinoplanes minutisporangius Ruan et al. 1986 and 'Actinoplanes aurantiacus' IFO 13967 to the genus Cryptosporangium as Cryptosporangium minutisporangium comb. nov. and Cryptosporangium aurantiacum sp. nov.
\end{abstract}

Keywords: Actinoplanes, family Micromonosporaceae, Cryptosporangium minutisporangium, Cryptosporangium aurantiacum, 16S rRNA

\section{Introduction}

The genus Actinoplanes (Couch 1950) emend. Stackebrandt and Kroppenstedt 1987 is a member of the family Micromonosporaceae (Krassil'nikov 1938) emend. Stackebrandt et al. 1997. Organisms placed in the genus Actinoplanes are characterized by the presence of spherical, cylindrical, digitate, lobate, bottleor flask-shaped or very irregular sporangia. Sporangiospores are motile by tufts of polar flagella. Aerial hyphae are scant. The peptidoglycan contains mesodiaminopimelic acid, which may be replaced by hydroxydiaminopimelic acid. Xylose is the diagnostic sugar of whole-cell hydrolysates and small amounts of galactose and/or arabinose are also frequently found. Phosphatidylethanolamine is the diagnostic phospho-

The DDBJ/GenBank/EMBL accession numbers for the 165 rRNA gene sequences determined in this study are shown in Figs 1 and 2 . lipid. Iso-/anteiso-branched and monounsaturated fatty acids and/or cis-9,10-octadecanoic acid (oleic acid) are predominant. The predominant isoprenoid quinone is $\mathrm{MK}-9\left(\mathrm{H}_{4}\right)$. The $\mathrm{G}+\mathrm{C}$ content of DNA ranges from $72 \cdot 1$ to $72.6 \mathrm{~mol} \%$. The type species is Actinoplanes philippinensis Couch 1950 and more than 20 species have been validly described.

Stackebrandt \& Kroppenstedt (1987) proposed the union of the genera Actinoplanes, Amorphosporangium Couch 1963 and Ampullariella Couch 1964 on the basis of chemotaxonomic properties, DNA pairing experiments, rRNA cistron similarity studies and a 16S rRNA oligonucleotide catalogue. Actinoplanes campanulatus, Actinoplanes digitatis, Actinoplanes lobatus and Actinoplanes regularis were formerly members of the genus Ampullariella and Actinoplanes auranticolor and Actinoplanes globisporus were formerly members of the genus Amorphosporangium. Actinoplanes armeniacus (Kalakoutskii \& Kusnetsov, 


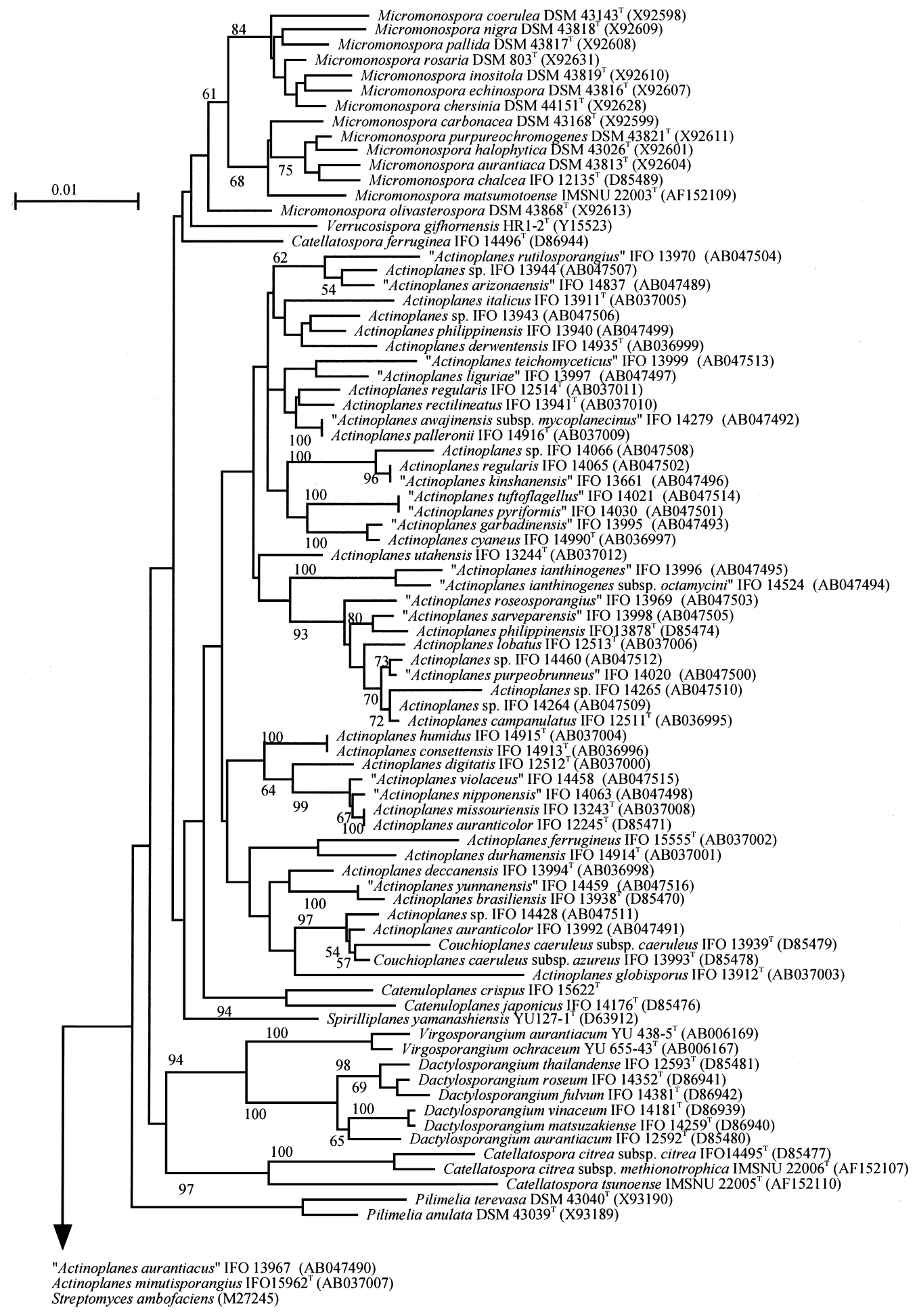

Fig. 1. Phylogenetic tree, based on neighbour-joining (Saitou \& Nei, 1987), derived from 165 rRNA sequences of valid species of the genus Actinoplanes and other members of the family Micromonosporaceae. Streptomyces ambofaciens ATCC $23877^{\top}$ (M27245) was used as the root organism. Bar, $0.01 K_{\text {nuc }}$ in nucleotide sequences. The numbers on the branches are confidence limits (expressed as percentages) estimated from a bootstrap analysis with 1000 replicates (only values above $50 \%$ are indicated). 


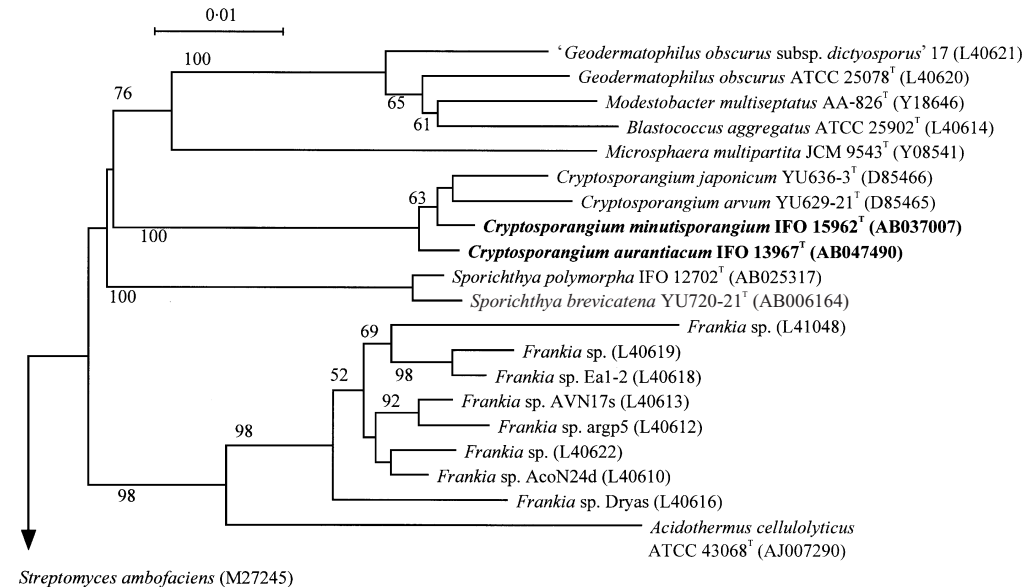

Fig. 2. Phylogenetic tree, based on neighbour-joining (Saitou \& Nei, 1987), derived from 16S rRNA sequences of the members of the suborder Frankineae. Streptomyces ambofaciens ATCC $23877^{\top}$ (M27245) was used as the root organism. Bar, $0.01 K_{\text {nuc }}$ in nucleotide sequences. The numbers on the branches are confidence limits (expressed as percentages) estimated from a bootstrap analysis with 1000 replicates (only values above $50 \%$ are indicated).

1964) was transferred to the genus Streptomyces as Streptomyces armeniacus (Wellington \& Williams, 1981) on the basis of its morphology, cell wall chemotype and phage susceptibility. Actinoplanes caeruleus (Horan \& Brodsky, 1986) was transferred to the genus Couchioplanes as Couchioplanes caeruleus (Tamura et al., 1994) on the basis of its morphology, chemotaxonomy and phylogeny. Goodfellow et al. (1990) determined the chemotaxonomic and phenotypic characteristics of species of Actinoplanes and reported that the chemical and numerical taxonomic data supported the integrity of the genus. Koch et al. (1996) analysed a $500 \mathrm{nt}$ stretch of 16S rDNA from 17 valid species of the genus Actinoplanes and reported that two major phylogenetic groups were detected. One contained Actinoplanes philippinensis and Actinoplanes brasiliensis and the other contained Actinoplanes cyaneus and Actinoplanes regularis.

In order to provide a basis for determining the phylogenetic relationships among the species of the genus Actinoplanes, we analysed the $16 \mathrm{~S}$ rDNAs of all validly described species as well as some invalid species belonging to the genus.

\section{METHODS}

Micro-organisms and culture conditions. The strains investigated in this study were 21 type strains of validly described Actinoplanes species and 28 other strains of Actinoplanes (Figs 1 and 2). All strains were cultivated at $28^{\circ} \mathrm{C}$ for $5 \mathrm{~d}$ in yeast extract/glucose broth (containing $10 \mathrm{~g}$ yeast extract and $10 \mathrm{~g}$ D-glucose in $1000 \mathrm{ml}$ distilled water, $\mathrm{pH} \mathrm{7.0)}$ on a rotary shaker.

PCR amplification and sequencing of 16S rDNA. 16S rDNA was amplified by PCR (Saiki et al., 1988) using protocols described previously (Tamura et al., 1998). The $1.5 \mathrm{~kb}$ amplified 16S rDNA was subjected to cycle sequencing by using a BigDye Terminator cycle sequencing kit in conjunction with Amplitaq FS (PE Applied Biosystems) and a Gene Amp PCR System 9700 (Perkin Elmer) according to the manufacturer's protocol with the following primers: $9 \mathrm{~F}$, 515F (5'-GTGCCAGCAGCCGCGGT-3', positions 515-
531), 785F (5'-GGATTAGATACCCTGGTAGTC-3', 785-805), 1099F (5'-GCAACGAGCGCAACCC-3', 10991114), 536R (5'-GTATTACCGCGGCTGCTG-3'， 536519), 802R (5'-TACCAGGGTATCTAATCC-3', 802-785), 1115R (5'-AGGGTTGCGCTCGTTG-3', 1115-1100) and $1541 \mathrm{R}$. The conditions for thermal cycling were 25 cycles of denaturation at $96{ }^{\circ} \mathrm{C}$ for $10 \mathrm{~s}$, primer annealing at $50{ }^{\circ} \mathrm{C}$ for $5 \mathrm{~s}$ and primer extension at $60^{\circ} \mathrm{C}$ for $4 \mathrm{~min}$. The products were purified as recommended by PE Applied Biosystems and were analysed with a model ABI PRISM 310 Genetic Analyzer (PE Applied Biosystems) according to the manufacturer's protocol.

Phylogenetic analysis. 16S rDNA sequences of the strains under investigation and reference organisms were aligned against that of Streptomyces ambofaciens (Pernodet et al., 1989). CLUSTAL W version 1.7 (Thompson et al., 1994) was used to generate evolutionary distances (the $K_{\text {nuc }}$ value of Kimura, 1980), similarity values, neighbour-joining analysis (Saitou \& Nei, 1987) from $K_{\text {nuc }}$ values and the bootstrap resampling method of Felsenstein (1985) with 1000 replicates for evaluation of the topology of the phylogenetic tree. NJplot (Perrière \& Gouy, 1996) was used to plot the phylogenetic tree.

The nucleotide sequence data reported in this paper will appear in the DDBJ, EMBL and GenBank nucleotide sequence databases with the accession numbers listed in Figs 1 and 2.

Analyses of chemotaxonomic characteristics. Analyses of whole-cell sugar composition, amino acid composition of cell wall, menaquinone composition, cellular fatty acid composition, isomers of diaminopimelic acid, acyl type of peptidoglycan, mycolic acid and DNA base composition were performed as described previously (Tamura et al., 1994).

Cultural, physiological and morphological characteristics. Cultural and physiological characteristics were determined as described previously (Yokota et al., 1993; Gordon et al., 1974). Morphology was observed by scanning electron microscopy as described previously (Tamura et al., 2000).

DNA-DNA hybridization. The microplate-hybridization method developed by Ezaki et al. (1988, 1989) was applied with minor modifications to determine DNA similarity (Tamura et al., 1999). 


\section{RESULTS AND DISCUSSION}

Almost complete 16S rRNA sequences were determined and analysed phylogenetically. Fig. 1 shows the phylogenetic tree derived from the 16S rDNA sequences of 21 type strains of validly described Actinoplanes species, 28 other strains of Actinoplanes and other members of the family Micromonosporaceae. With the exception of Actinoplanes minutisporangius IFO $15962^{\mathrm{T}}$ and 'Actinoplanes aurantiacus' IFO 13967, the members of the genus Actinoplanes belonged phylogenetically to the family Micromonosporaceae. However, they did not form a stable cluster within the family; most branches had only low bootstrap values and the clustering might change if the operational taxonomic unit were changed.

On other hand, some strains were phylogenetically related. Actinoplanes missouriensis IFO $13243^{\mathrm{T}}$ and Actinoplanes auranticolor IFO $12245^{\mathrm{T}}$ had $99.8 \%$ sequence similarity. However, these species have many differences in physiological characteristics (Goodfellow et al., 1990).

Actinoplanes humidus and Actinoplanes consettensis, which were isolated from sediments of the River Derwent in the UK (Goodfellow et al., 1990), had $100 \%$ sequence similarity. However, in their physiological characteristics, these species are distinguishable by the reduction of nitrate (Goodfellow et al., 1990). DNA-DNA hybridization studies may be required to confirm that they are phenotypically defined species.

Actinoplanes campanulatus, Actinoplanes digitatis, Actinoplanes lobatus and Actinoplanes regularis, which were members of the former genus Ampullariella, did not form a coherent cluster within the genus. The same is true of Actinoplanes auranticolor and Actinoplanes globisporus, members of the former genus Amorphosporangium. Actinoplanes globisporus IFO $13912^{\mathrm{T}}$ has the longest branch among the type strains of validly described Actinoplanes species, excluding Actinoplanes minutisporangius IFO $15962^{\mathrm{T}}$, and its similarity to the type strains of validly described Actinoplanes species ranged from 94.8 to $96.9 \%$. For the type strains of validly described Actinoplanes species other than Actinoplanes minutisporangius IFO $15962^{\mathrm{T}}$ and Actinoplanes globisporus IFO $13912^{\mathrm{T}}$, the levels of $16 \mathrm{~S}$ rDNA sequence similarity were greater than $95.7 \%$. The chemotaxonomic characteristics of Actinoplanes globisporus IFO $13912^{\mathrm{T}}$ were in good agreement with those of the genus Actinoplanes (Table 1), thus confirming its assignment to this genus.

Actinoplanes sp. IFO 14428 and Actinoplanes auranticolor IFO 13992 formed a cluster with strains of Couchioplanes. In neither strain was the sheath of sporangia observable by scanning electron microscope (data not shown), and this morphological feature is characteristic of strains belonging to the genus Couchioplanes. However, both strains had mesodiaminopimelic acid as the diamino acid of the peptidoglycan, while the members of the genus Couchioplanes have lysine.

Actinoplanes minutisporangius IFO $15962^{\mathrm{T}}$ and 'Actinoplanes aurantiacus' IFO 13967 were placed outside the family Micromonosporaceae (Fig. 1) and were found to be related to members of the genus Cryptosporangium (Tamura et al., 1998) (Fig. 2). Actinoplanes minutisporangius IFO $15962^{\mathrm{T}}$ and 'Actinoplanes aurantiacus' IFO 13967 had 98.0-99.3\% similarity to members of the genus Cryptosporangium, but less than $93.7 \%$ similarity to other Actinoplanes species. Actinoplanes minutisporangius was reported to produce spherical and subspherical sporangia above and within agar (Ruan et al., 1985), which is consistent with the morphological characteristics of the genus Cryptosporangium (Tamura et al., 1998). The major menaquinone and fatty acid patterns of Actinoplanes minutisporangius IFO $15962^{\mathrm{T}}$ and members of Cryptosporangium were also in good agreement (Table 1). Thus, on the basis of morphological, physiological, chemotaxonomic and phylogenetic criteria, Actinoplanes minutisporangius IFO $15962^{\mathrm{T}}$ is considered to

Table 1. Chemotaxonomic characteristics of species of Actinoplanes and Cryptosporangium

All taxa have glutamic acid, alanine, glycine, 3-hydroxydiaminopimelic acid and meso-diaminopimelic acid as cell wall amino acids. Pooled data were taken from Goodfellow et al. (1990) (Actinoplanes) and Tamura et al. (1999) (Cryptosporangium).

\begin{tabular}{|c|c|c|c|c|}
\hline Characteristic & $\begin{array}{l}\text { A. globisporus } \\
\text { IFO } 13912^{\mathrm{T}}\end{array}$ & Actinoplanes & $\begin{array}{c}\text { A. minutisporangius } \\
\text { IFO } 15962^{\mathrm{T}} \text { and } \\
\text { 'A. aurantiacus' IFO } 13967\end{array}$ & Cryptosporangium \\
\hline $\begin{array}{l}\text { Major menaquinones } \\
\text { Major cellular } \\
\text { fatty acid(s) }\end{array}$ & $\begin{array}{l}8\left(\mathrm{H}_{4}\right), 9\left(\mathrm{H}_{6}\right), 9\left(\mathrm{H}_{8}\right) \\
\text { iso- } \mathrm{C}_{16: 0}\end{array}$ & $\begin{array}{l}9\left(\mathrm{H}_{4}\right), 9\left(\mathrm{H}_{6}\right), 8\left(\mathrm{H}_{2}\right) \\
\text { anteiso- } \mathrm{C}_{15: 0}, \mathrm{C}_{17: 0}, \\
\text { iso- }_{16: 0}, \text { anteiso- } \mathrm{C}_{17: 0}, \\
\mathrm{C}_{18: 0}, \mathrm{C}_{19: 0}, \text { iso- } \mathrm{C}_{15: 0}, \\
\mathrm{C}_{16: 0}, \mathrm{C}_{18: 1}\end{array}$ & $\begin{array}{l}9\left(\mathrm{H}_{2}\right), 9\left(\mathrm{H}_{6}\right), 9\left(\mathrm{H}_{8}\right) \\
\text { iso- } \mathrm{C}_{16: 0}, \mathrm{C}_{18: 1}\end{array}$ & $\begin{array}{l}9\left(\mathrm{H}_{6}\right), 9\left(\mathrm{H}_{8}\right), 9\left(\mathrm{H}_{4}\right) \\
\text { iso- } \mathrm{C}_{16: 0}, \mathrm{C}_{18: 1}, \mathrm{C}_{17: 1}\end{array}$ \\
\hline $\begin{array}{l}\text { Presence of } \\
\text { 2-OH fatty acids }\end{array}$ & + & $+/-$ & - & - \\
\hline
\end{tabular}


Table 2. Differential characteristics of species belonging the genus Cryptosporangium

Data not obtained in this study were taken from Ruan et al. (1985) (C. minutisporangium) and Tamura et al. (1998) (C. arvum and C. japonicum). All of the strains listed gave good growth at 20 and $25^{\circ} \mathrm{C}$ and no growth at $45^{\circ} \mathrm{C}$. + , Positive; - , negative; w, weakly positive; $d$, positive or negative.

\begin{tabular}{|c|c|c|c|c|}
\hline Characteristic & $\begin{array}{c}\text { C. minutisporangium } \\
\text { IFO } 15962^{\mathrm{T}}\end{array}$ & $\begin{array}{l}\text { C. aurantiacum } \\
\text { IFO } 13967^{\mathrm{T}}\end{array}$ & $\begin{array}{c}\text { C. arvum } \\
\text { YU629-21 }\end{array}$ & $\begin{array}{l}\text { C. japonicum } \\
\text { YU636-3 }\end{array}$ \\
\hline \multicolumn{5}{|l|}{ Acid production from: } \\
\hline $\mathrm{D}(+)$-Maltose & + & - & + & + \\
\hline $\mathrm{D}(+)$-Lactose & + & - & + & + \\
\hline$i$-Inositol & - & $\mathrm{d}$ & + & + \\
\hline Methyl $\alpha$-D-glucoside & + & - & + & - \\
\hline \multicolumn{5}{|l|}{ Utilization of carbohydrates: } \\
\hline$i$-Inositol & w & $\mathrm{w}$ & + & + \\
\hline D-Sorbitol & - & $\mathrm{W}$ & - & $\mathrm{d}$ \\
\hline $\mathrm{D}(+)$-Raffinose & w & - & + & $\mathrm{d}$ \\
\hline Decomposition of urea & + & - & - & - \\
\hline \multicolumn{5}{|l|}{ Hydrolysis of: } \\
\hline Starch & + & + & - & - \\
\hline Urea & + & - & - & - \\
\hline Gelatin & + & - & - & - \\
\hline \multicolumn{5}{|l|}{ Utilization of organic acids: } \\
\hline Succinate & + & - & - & - \\
\hline Oxalate & - & + & - & - \\
\hline Malate & + & - & - & - \\
\hline Nitrite from nitrate & + & + & - & - \\
\hline Decomposition of calcium malate & - & - & + & + \\
\hline Pigmentation in ISP 7 & - & Moderate red & Pale reddish brown & Pale reddish brown \\
\hline \multicolumn{5}{|l|}{ Growth at $\left({ }^{\circ} \mathrm{C}\right):^{*}$} \\
\hline 10 & + & - & - & - \\
\hline 15 & + & $\mathrm{W}$ & ++ & + \\
\hline 30 & ++ & ++ & + & + \\
\hline 37 & - & ++ & - & + \\
\hline
\end{tabular}

* Growth is scored as: ++ , good; + , moderate; w, weak; - , no growth.

belong to the genus Cryptosporangium rather than the genus Actinoplanes.

The chemotaxonomic characteristics of 'Actinoplanes aurantiacus' IFO 13967 are also consistent with those of the genus Cryptosporangium (Table 1). DNA-DNA hybridization was performed between Actinoplanes minutisporangius IFO $15962^{\mathrm{T}}$, Actinoplanes aurantiacus IFO $13967^{\mathrm{T}}$, Cryptosporangium arvum YU 629-2 $1^{\mathrm{T}}$ and Cryptosporangium japonicum $\mathrm{YU}$ 636- $3^{\mathrm{T}}$, YU 655-31 and YU 656-31. Actinoplanes minutisporangius IFO $15962^{\mathrm{T}}$ exhibited levels of DNA-DNA relatedness of $14-22 \%$ to other strains. 'Actinoplanes aurantiacus' IFO 13967 exhibited levels of DNADNA relatedness of $15-21 \%$ to other strains. All other species of Cryptosporangium developed orange-yellow substrate mycelium on most media, but Actinoplanes minutisporangius developed brown to brownish black substrate mycelium (Ruan et al., 1985). Actinoplanes minutisporangius also differed from other members of the genus Cryptosporangium in the hydrolysis of starch and gelatin and the reduction of nitrate (Table 2).
Similarly, 'Actinoplanes aurantiacus' IFO 13967 differed from other members of the genus Cryptosporangium in the utilization of raffinose, hydrolysis of starch and reduction of nitrate (Table 2). These results indicate that this strain represents a novel species of the genus Cryptosporangium. We therefore propose that Actinoplanes minutisporangius IFO $15962^{\mathrm{T}}$ be transferred to the genus Cryptosporangium as Cryptosporangium minutisporangium comb. nov. and that 'Actinoplanes aurantiacus' IFO 13967 be accepted as a novel species of the genus Cryptosporangium, Cryptosporangium aurantiacum $\mathrm{sp}$. nov.

\section{Description of Cryptosporangium minutisporangium comb. nov.}

Basonym: Actinoplanes minutisporangius Ruan et al. 1986.

The description is based on the data compiled by Ruan et al. (1985) and in this study. Morphological, chemo- 
taxonomic and general characteristics are as given previously for the genus (Tamura et al., 1998). Spores are motile. Brown to brownish black substrate mycelium is produced. Hydrolyses casein, hypoxanthine, urea, starch and gelatin. Does not hydrolyse adenine or xanthine. Reduces nitrate to nitrite. Phosphatase is negative. Acetate, malate, pyruvate, succinate and propionate are utilized, but lactate, benzoate, citrate, mucate, oxalate and tartrate are not utilized. Acid is produced from arabinose, cellobiose, fructose, galactose, glucose, glycerol, inositol, lactose, maltose, mannitol, mannose, melibiose, methyl $\alpha$-D-glucoside, rhamnose, salicin, sucrose, trehalose and xylose, but is not produced from adonitol, dulcitol, erythritol, raffinose, sorbitol or methyl $\alpha$-D-xyloside. The $\mathrm{G}+\mathrm{C}$ content of the DNA is $76 \mathrm{~mol} \%\left(T_{\mathrm{m}}\right)$. Habitat: soil.

The type strain is IFO $15962^{\mathrm{T}}\left(=\mathrm{JCM} 9458^{\mathrm{T}}=\mathrm{ATCC}\right.$ $49415^{\mathrm{T}}=\mathrm{LL}-\mathrm{A}-60^{\mathrm{T}}$ ).

\section{Description of Cryptosporangium aurantiacum sp. nov.}

Cryptosporangium aurantiacum (au.ran.ti.ac'um. M.L. neut. adj. aurantiacum orange-coloured).

Morphological, chemotaxonomic and general characteristics are as given for the genus. Moderate red soluble pigment is produced on tyrosine agar (ISP medium 7). Starch is hydrolysed. Gelatin and aesculin are not hydrolysed. Nitrate is reduced. No growth at $4 \% \mathrm{NaCl}$. Acid is produced from mannitol, melibiose, rhamnose, arabinose, galactose, mannose, glucose and xylose, but not from erythritol, adonitol, maltose, lactose, sorbitol, methyl $\alpha$-D-glucoside, dulcitol or raffinose. Mannitol, melibiose, maltose, rhamnose, lactose, inositol, sorbitol, arabinose, galactose, mannose, glucose, xylose and oxalate are utilized, but erythritol, adonitol, methyl $\alpha$-D-glucoside, dulcitol, raffinose, succinate, malate and citrate are not. Habitat: cultivated soil.

The type strain is IFO $13967^{\mathrm{T}}\left(=\mathrm{JCM} 3241^{\mathrm{T}}=71-\right.$ $\left.\mathrm{C} 38^{\mathrm{T}}\right)$.

\section{REFERENCES}

Couch, J. N. (1950). Actinoplanes, a new genus of the Actinomycetales. J Elisha Mitchell Sci Soc 66, 87-92.

Couch, J. N. (1963). Some new genera and species of the Actinoplanaceae. J Elisha Mitchell Sci Soc 79, 53-70.

Couch, J. N. (1964). A proposal to replace the name Ampullariella. J Elisha Mitchell Sci Soc 80, 29.

Ezaki, T., Hashimoto, Y., Takeuchi, N., Yamamoto, H., Liu, S.-L., Miura, H., Matsui, K. \& Yabuuchi, E. (1988). Simple genetic method to identify viridans group streptococci by colorimetric dot hybridization and fluorometric hybridization in microdilution wells. J Clin Microbiol 26, 1708-1713.

Ezaki, T., Hashimoto, Y. \& Yabuuchi, E. (1989). Fluorometric deoxyribonucleic acid-deoxyribonucleic acid hybridization in microdilution wells as an alternative to membrane filter hybridization in which radioisotopes are used to determine genetic relatedness among bacterial strains. Int $J$ Syst Bacteriol 39, 224-229.

Felsenstein, J. (1985). Confidence limits on phylogenies: an approach using the bootstrap. Evolution 39, 783-791.

Goodfellow, M., Stanton, L. J., Simpson, K. E. \& Minnikin, D. E. (1990). Numerical and chemical classification of Actinoplanes and some related actinomycetes. J Gen Microbiol 136, 19-36.

Gordon, R. E., Barnett, D. A., Handerhan, J. E. \& Pang, C. H.-N. (1974). Nocardia coeliaca, Nocardia autotrophica, and the nocardin strain. Int J Syst Bacteriol 24, 54-63.

Horan, A. C. \& Brodsky, B. (1986). Actinoplanes caeruleus sp. nov., a blue-pigmented species of the genus Actinoplanes. Int $J$ Syst Bacteriol 36, 187-191.

Kalakoutskii, L. V. \& Kusnetsov, V. D. (1964). A new species of the Actinoplanes $-A$. armeniacus and some peculiarities of its mode of spore formation. Mikrobiologiya 33, 613 .

Kimura, M. (1980). A simple method for estimating evolutionary rates of base substitutions through comparative studies of nucleotide sequences. J Mol Evol 16, 111-120.

Koch, C., Kroppenstedt, R. M. \& Stackebrandt, E. (1996). Intrageneric relationships of the actinomycete genus Micromonospora. Int J Syst Bacteriol 46, 383-387.

Krassil'nikov, N. A. (1938). Ray Fungi and Related Organisms, Actinomycetales. Moscow: Izdatel'stvo Akademii Nauk SSSR (in Russian).

Pernodet, J.-L., Boccard, F., Alegre, M.-T., Gagnat, J. \& Guérineau, M. (1989). Organization and nucleotide sequence analysis of a ribosomal RNA gene cluster from Streptomyces ambofaciens. Gene 79, 33-46.

Perrière, G. \& Gouy, M. (1996). WWW-query: an on-line retrieval system for biological sequence banks. Biochimie 78, 364-369.

Ruan, J.-S., Lechevalier, M. P., Jiang, C.-R. \& Lechevalier, H. A. (1985). A new species of the genus Actinoplanes, Actinoplanes minutisporangius n. sp. Actinomycetes 19, 163-175.

Saiki, R. K., Gelfand, D. H., Stoffel, S., Scharf, S. J., Higuchi, R., Horn, G. T., Mullis, K. B. \& Erlich, H. A. (1988). Primer-directed enzymatic amplification of DNA with a thermostable DNA polymerase. Science 239, 487-491.

Saitou, N. \& Nei, M. (1987). The neighbor-joining method: a new method for reconstructing phylogenetic trees. Mol Biol Evol 4, 406-425.

Stackebrandt, E. \& Kroppenstedt, R. M. (1987). Union of the genera Actinoplanes Couch, Ampullariella Couch, and Amorphosporangium Couch in a redefined genus Actinoplanes. Syst Appl Microbiol 9, 110-114.

Stackebrandt, E., Rainey, F. A. \& Ward-Rainey, N. L. (1997). Proposal for a new hierarchic classification system, Actinobacteria classis nov. Int J Syst Bacteriol 47, 479-491.

Tamura, T., Nakagaito, Y., Nishii, T., Hasegawa, T., Stackebrandt, E. \& Yokota, A. (1994). A new genus of the order Actinomycetales, Couchioplanes gen. nov., with descriptions of Couchioplanes caeruleus (Horan and Brodsky 1986) comb. nov. and Couchioplanes caeruleus subsp. azureus subsp. nov. Int J Syst Bacteriol 44, 193-203.

Tamura, T., Hayakawa, M. \& Hatano, K. (1998). A new genus of the order Actinomycetales, Cryptosporangium gen. nov., with descriptions of Cryptosporangium arvum sp. nov. and Cryptosporangium japonicum sp. nov. Int J Syst Bacteriol 48, 995-1005.

Tamura, T., Hayakawa, M. \& Hatano, K. (1999). Sporichthya brevicatena sp. nov. Int J Syst Bacteriol 49, 1779-1784. 
Tamura, T., Suzuki, S. \& Hatano, K. (2000). Acrocarpospora gen. nov., a new genus of the order Actinomycetales. Int $J$ Syst Evol Microbiol 50, 1163-1171.

Thompson, J. D., Higgins, D. G. \& Gibson, T. J. (1994). CLUSTAL $\mathrm{W}$ : improving the sensitivity of progressive multiple sequence alignment through sequence weighting, position-specific gap penalties and weight matrix choice. Nucleic Acids Res 22, 4673-4680.
Wellington, E. M. H. \& Williams, S. T. (1981). Transfer of Actinoplanes armeniacus Kalakoutskii and Kusnetsov to Streptomyces: Streptomyces armeniacus (Kalakoutskii and Kusnetsov) comb. nov. Int J Syst Bacteriol 31, 77-81.

Yokota, A., Tamura, T., Hasegawa, T. \& Huang, L. H. (1993). Catenuloplanes japonicus gen. nov., sp. nov., nom. rev., a new genus of the order Actinomycetales. Int J Syst Bacteriol 43, 805-812. 